\title{
LA POLÍTICA COMO HEGEMONÍA EN LA OBRA DE LACLAU: ENTRE LA FILOSOFÍA ORACULAR Y EL LIDERAZGO CARISMÁTICO
}

\section{Resumen/Abstract}

\author{
José Fernando García ${ }^{1}$
}

El artículo analiza la concepción de lo político en la obra de Ernesto Laclau desde una mirada pragmática, mostrando que la noción de hegemonía encierra a las prácticas políticas en una ontología de origen semiológico que, pese a sus declaraciones, tiene como resultado una posición esencialista, implicando la impotencia de la práctica política para trascender lo político. La primacía del significante de la semiología es contrastada con los derechos del significado en la concepción pragmática, donde las prácticas establecen el significado de lo político, siendo la función de la filosofía elevarlas a reflexión. Como contrapartida, el enfoque semiológico de Laclau, junto a una concepción oracular de la teoría, asume una idea de decisión cuya implicación es que ésta quede reservada a un liderazgo carismático. ${ }^{2}$

Palabras clave: la política, lo político, hegemonía, semiología, pragmática, decisión

\section{THE POLITICAL AS HEGEMONY IN THE WORK OF LACLAU: BETWEEN ORACULAR PHILOSOPHY AND CHARISMATIC LEADERSHIP}

The article analyses the conception of the political in the work of Ernesto Laclau from a pragmatic view, showing that the notion of hegemony imprisons politics in an ontology of semiotic origin that, despite their statements, result in an essentialist position, implying impotence of political practices to transcend the political. The primacy of the signifier of semiotics is contrasted with the rights of meaning in the pragmatic conception, in which practices establishes the meaning of politics, and the function of philosophy is raise them to reflection. In return, the semiotic approach of Laclau, in addition to an oracular conception of theory, assumes an idea of decision whose implication is that it is restricted to a charismatic leadership.

Keywords: politics, the political, hegemony, semiotics, pragmatic, decision

\footnotetext{
${ }^{1}$ Universidad Academia de Humanismo Cristiano. E-mail: jgarcias@docentes.academia.cl

${ }^{2}$ Laclau ha elaborado su obra en estrecha colaboración con Chantal Mouffe. No obstante, cada cual ha producido textos propios en los que se aprecian diferencias de enfoque y énfasis individuales. Un estudio comparativo tendría que ser motivo de otra investigación. He optado, entonces, por limitarme a los textos de Laclau, tomando en consideración solamente un texto publicado por ambos -Laclau y Mouffe 1987- dado su carácter programático.
} 
Para Ernesto Laclau la elaboración del concepto de hegemonía -que reconoce sus antecedentes en Gramcsi- exige avanzar en un proceso de formalización de un análisis hasta el momento sociológico y descriptivo. La tarea que eso plantea es el entendimiento de la lógica de las operaciones implicadas en la constitución de los procesos hegemónicos. Señala que el análisis formal es necesario en un doble sentido, puesto que no solamente toda construcción teórica de un objeto lo supone sino también porque la realidad social misma genera abstracciones que organizan su propio principio de funcionamiento; no se trata, pues, de abstracciones puramente analíticas sino reales, de las cuales dependen las identidades y articulaciones políticas (Laclau 2011: 60). El enfoque corresponde, como vemos, a un análisis trascendental, a una lógica en cuanto se ocupa de objetos, en un sentido similar al introducido por Kant (Kant 2006: 97).

Laclau sostiene que toda práctica es discursiva, entendiendo por discurso el conjunto de reglas de un juego de lenguaje junto a aquellas acciones "que las implementan/distorsionan/subvierten" (Laclau 2011: 284). A su vez, por lógica entiende "el tipo de relaciones entre entidades que hace posible que ese tipo de reglas funcione" (Laclau 2011: 283). Agrega que el discurso opera en el plano óntico, mientras la lógica en un nivel ontológico. Laclau sigue al Foucault de la Arqueología del saber, pero alejándose de él en cuanto éste toma un derrotero histórico. Dice Foucault: "En fin, lo que se llama práctica discursiva puede ser precisado ahora (....) es un conjunto de reglas anónimas, históricas, siempre determinadas en el tiempo y el espacio que han definido en una época dada y para un área social, económica, geográfica o lingüística dada las condiciones de ejercicio de la función enunciativa" (Foucault 2002: 198).

De acuerdo a Laclau, la caída de la concepción de un cosmos del cual el hombre era parte y la emergencia de una visión en la que éste mantiene relaciones de exterioridad con el universo, a partir del siglo XVII, implicó la imposibilidad de seguir pensando en la realidad social como una totalidad estructural u orgánica (Laclau y Mouffe 1987: 106). Con la Revolución Francesa se inaugura en Occidente una nueva matriz del imaginario social, un punto nodal de la construcción de lo político, el que permite plantear las diferentes formas de desigualdad como ilegítimas y hacerlas equivalentes a distintas formas de opresión (Laclau y Mouffe 1987: 173 y ss.). Eso implica que la política hegemónica se impone en la modernidad en la medida que se incrementa el carácter abierto, no suturado de lo social y las reivindicaciones socialistas deben ser vistas como parte de la revolución democrática. Consecuentemente, "la pluralidad no es el fenómeno a explicar, sino el punto de partida 
del análisis" (Laclau y Mouffe 1987: 161).

Las prácticas discursivas son prácticas articulatorias de una pluralidad de significantes flotantes en una totalidad estructurada, los cuales, sin embargo, no logran ser totalmente incorporados a la misma. ${ }^{3}$ El discurso es un intento siempre fracasado por dominar el campo de la discursividad, las prácticas articulatorias establecen puntos nodales que fijan parcialmente el sentido de los elementos flotantes. La transición de los 'elementos flotantes' a 'momentos' de una estructura nunca es completa, de ahí el constante desbordamiento de todo discurso y la apertura de lo social. El concepto de sobre-determinación corresponde a un tipo de 'fusión' simbólica que supone una pluralidad de sentidos los cuales reenvían unos a otros, un campo de identidades que nunca logran ser fijadas totalmente.

No es posible el cierre de una totalidad discursiva sea a través de la objetividad como tampoco de una subjetividad, dado que ambas están también sobre determinadas discursivamente. “'Objetivismo' y 'subjetivismo', 'totalismo' e 'individualismo' son expresiones simétricas del deseo de una plenitud que es permanentemente diferida" (Worsham \& Olson 1999: 140). Lo social es "imposible", articulación nunca lograda del todo, siempre desbordada, resultado de esfuerzos parciales orientados a limitar la contingencia (Worsham \& Olson 1999: 131). La articulación contingente en la cual consisten las prácticas sociales existe al interior de lo necesario, dado que toda identidad es relacional y esas relaciones tienen un carácter necesario. "La necesidad de lo social es la necesidad propia de las identidades puramente relacionales -como en el caso del principio lingüístico del valor-; no la necesidad natural o la necesidad de un juicio analítico. 'Necesario', en tal sentido, equivale simplemente a 'sistema de posiciones diferenciales en un espacio suturado'" (Ibíd.).

Laclau deriva el antagonismo de lo social de su condición discursiva y de la imposibilidad de lograr identidades sociales plenas. El límite de lo social es interior al mismo y el antagonismo surge

\footnotetext{
3 "Si Ud. quiere concebir la articulación puede recurrir, por ejemplo, al modelo saussuriano. En el modelo suassuriano, en cuanto el lenguaje es un sistema de diferencias, eso significa, por una parte, que la totalidad social está, en algún sentido presupuesta, digamos, por la totalidad significante. La totalidad significante está presupuesta por todo acto singular de significación, pero, al mismo tiempo está expuesta a nuevos elementos porque los nuevos elementos van a producir una nueva articulación de todo lo que está dentro de la estructura. Así, articulación en este sentido se convierte en la categoría básica del análisis social, en tanto todas las prácticas sociales son prácticas significantes" (Worsham, \& Olson 1999: 11). Todas las citas de este texto corresponden a respuestas de Laclau a la interrogación de los editores.

4 También: (...) puesto que la identidad depende enteramente de condiciones de existencia que son contingentes, su relación con éstas últimas es absolutamente necesaria. Lo que encontramos, por lo tanto, es una relación de imbricación completa entre ambos: la esencia no es nada al margen de los accidentes" (Laclau 1993: 37).
} 
como su negación, lo que implica que deba manifestarse como subversión. “(...) el antagonismo constituye los límites de toda objetividad -que se revela como objetivación parcial y precaria (...)" (Laclau y Mouffe 1987: 145). El antagonismo se ubica en los límites del lenguaje y existe como su disrupción, escapando a la posibilidad de ser aprehendido como tal, dado que es la imposibilidad de suturar lo social. El antagonismo y la subversión de lo social se llevan a cabo a través de la relación de equivalencia de las diferencias, las cuales son anuladas y pasan a expresar algo idéntico a todas ellas. "De ahí la ambigüedad que penetra toda relación de equivalencia: dos términos para equivalerse, deben ser diferentes (de lo contrario se trataría de una simple identidad). Pero, por otro lado, la equivalencia sólo existe en el acto de subvertir el carácter diferencial de esos términos. Este es punto en el que, según dijimos antes, lo contingente subvierte lo necesario" (Laclau y Mouffe 1987: 148).

De acuerdo a lo anterior, ciertas formas discursivas a través de la equivalencia anulan las diferencias y la positividad de los objetos de otras formas discursivas y dan existencia real a la negatividad. Cualquier posición en un sistema de diferencias en cuanto es negada a través de la equivalencia puede constituirse en antagonismo. Pero ni la diferencia ni la equivalencia logran estabilizarse como tales, en la medida que coexisten como subversión recíproca, y eso implica que, aunque la sociedad no es posible, tampoco es imposible. "Esto nos permite formular la siguiente conclusión: si la sociedad no es nunca transparente para sí misma porque no logra constituirse como campo objetivo, tampoco es enteramente transparente a sí mismo el antagonismo, ya que no logra disolver totalmente la objetividad de lo social" (Laclau y Mouffe 1987: 150).

La relación de equivalencia de las diferencias se lleva a cabo a través de un particular que pasa a representar lo universal, sin perder esa condición. Dicha posibilidad supone que la dicotomía universalidad-particularidad sea superada, mediante "la producción de significantes tendencialmente vacíos que, mientras mantienen la inconmensurabilidad entre universal y particulares, permiten que los últimos tomen la representación del primero" (Laclau 2011: 62).

Hegemonía es el concepto fundamental que Laclau elabora en relación a lo político, el que responde a un tipo de práctica articulatoria específica. Sus condiciones son, por una parte, la presencia de fuerzas antagónicas, así como la inestabilidad de las fronteras que las separan, esto es, la presencia de elementos flotantes o potencialmente vacíos y su posible articulación en campos opuestos. De lo dicho se infiere que no hay nada de natural ni de inevitable en la lucha contra la desigualdad, la subordinación y el poder: no hay agentes privilegiados, como las clases, ni sustrato antropológico 
alguno que implique la lucha contra las mismas. "La lucha contra la subordinación no puede ser el resultado de la propia situación de subordinación” (Laclau y Mouffe 1987: 171). ¿Cuáles son las condiciones discursivas de una acción orientada a luchar contra las relaciones de subordinación? ¿cuándo las relaciones de subordinación se transforman en relaciones antagónicas? Eso ocurre cuando se produce una nueva articulación discursiva de las demandas en posiciones equivalenciales, las que son fijadas momentáneamente en un punto nodal que desafía la hegemonía existente. De modo que el campo discursivo de la revolución democrática abre espacio para diversas políticas, el populismo de derecha o la democracia radical, en cuanto las diferencias pueden ser articuladas o subvertidas en discursos totalmente diferentes.

\section{El enfoque trascendental como semiología generalizada}

En el debate con Laclau, Butler señala que éste localiza un nivel que estructura y condiciona lo social, distinguiéndose de él y que dicho análisis "separa el análisis formal del lenguaje de sus sintaxis sociales y culturales" (Butler 2011: 43). La respuesta de Laclau es que cualquier categoría social que pretenda dar cuenta de la efectividad estructural no puede sino hacerlo y que si esto no fuera así "la única opción sería el descriptivismo periodístico" (Laclau 2011:191).

Como vimos, la articulación contingente de elementos en la que consisten las prácticas sociales existe al interior de lo necesario. De más está decir que "necesario" implica universalidad y ahistoricidad, expresadas en aquellas "estructuras más estables del lenguaje que, hasta cierto punto, atraviesan las diferenciaciones culturales e históricas" (Laclau 2011: 192). Laclau, ciertamente, podría responder que la "necesidad" que plantea da lugar a la contingencia y al ejercicio de la política y la hegemonía en un contexto histórico; pero aquello insuperable es la condición hegemónica de la política, derivada del nivel estructural.

Cabe plantear que el punto no consiste en las determinaciones estructurales, sino en las características que Laclau les atribuye al alojarlas en "una semiología generalizada". Sostiene que, a pesar de haber ido más allá de Barthes, "la posibilidad de generalizar el uso de categorías lingüísticas para diversos niveles de organización social es tan válida como lo era en los sesenta" (Laclau 2011: 192). Agrega que eso no implica tomar las categorías formales con independencia del contexto, "sino como contaminadas y parcialmente deformadas por esos contextos" (Ibíd.). Sin embargo, ni la contaminación ni la deformación parcial implican una pérdida de identidad de las categorías, las que continúan siendo formales, esto es, cuya validez es independiente del contexto. De allí que Butler tenga razón cuando concluye: "entonces postulamos una exterioridad de la política con respecto al 
lenguaje que parece deshacer el concepto mismo de performatividad" (Butler 2011: 43).

A más de la "semiología generalizada" de origen saussuriano, en los análisis de Laclau juega un papel central la diferencia "óntico-ontológico" de filiación heideggeriana. No es, pues, casual que se refiera a las determinaciones históricas como "estructurales" u "ontológicas", indistintamente. Ahora bien, en ambas tradiciones las prácticas discursivas tienen un ámbito acotado de efectividad. En Heidegger, la apertura ontológica del mundo queda hipostasiada como un inicio que "prevalece sobre todo lo que ha de venir después" (Heidegger, 2016: s/p) y toda interpretación queda "de antemano iluminada y orientada por una comprensión del ser del ente" (Heidegger 1992: 67-68), siendo las prácticas discursivas impotentes para romper el círculo de dicha apertura, permaneciendo lo óntico, subordinado a lo ontológico. ${ }^{7}$ A su vez, la deconstrucción pone énfasis en que "lengua no es una función del sujeto hablante" ${ }^{\natural}$, de acuerdo a la expresión de Saussure, estableciendo un "imperio de los signos", de la cual el último Barthes intenta deshacerse. ${ }^{9}$ El concepto de hegemonía encierra las prácticas políticas no ya en el destino del inicio heideggeriano, pero sí en una ontología de origen semiológico. Laclau lo expresa del siguiente modo: "La barra S/s es la precondición misma de una primacía del significante sin la cual los desplazamientos hegemónicos serían inconcebibles" (Laclau 2011: 76). ${ }^{10}$ Así, la hegemonía al quedar inscrita en la semiología, supone la impotencia de la política para trascender lo político, fijándola de una vez para siempre como antagonismo, de modo esencialista. $^{11}$

Es pertinente recordar aquí que, como señaláramos, el propio Laclau alude al cambio histórico entre una realidad social pensada como totalidad estructural u orgánica de sentido y la fragmentación del mismo que caracterizaría a las sociedades modernas. Se puede pensar ese cambio histórico -el

5 El enunciado completo dice: "Porque el inicio de un destino es lo más grande. Prevalece sobre todo lo que ha de venir después."

6 El énfasis es agregado.

${ }^{7}$ Un mayor desarrollo de esto puede encontrarse en García 2016.

8 Dice Derrida: "Este aspecto económico de la diferencia, haciendo intervenir un cierto cálculo -no consciente- en un campo de fuerzas, es inseparable del aspecto estrechamente semiótico. Confirma que el sujeto, primero el sujeto consciente y parlante, depende de un sistema de diferencias y del movimiento de la diferencia, que no está presente y sobre todo presente a sí antes de la diferencia, que él no se constituye más que dividiéndose, espaciándose y 'temporalizándose', diferenciándose, y que, como lo dice Saussure 'la lengua (que no consiste más que en diferencias) no es una función del sujeto hablante'" (Derrida 1972: 41).

9 "Imperio de los signos, publicado originalmente en 1970, es reconocido como parte de la fase 'post-estructuralista' de Roland Barthes en la que su preocupación por explicar los sistemas de signos es superada por el deseo de interrumpir y descentrar su autoridad. Como texto, señala el abandono de la utilización de los elementos formales de la semiología -0 los principios rectores de la lingüística estructural- para estudiar los fenómenos reales del mundo de las prácticas culturales como imágenes y textos que pueden ser leídos " (Trifonas 2001:3).

${ }^{10}$ Me parece, pues, totalmente errada la apreciación de Geoff Boucher, quién dice: "Poniendo su teoría social en el terreno del significado Laclau y Mouffe no producen una teoría social deconstructiva sino una hermenéutica política reñida con los principios claves del postestructuralismo." (Boucher 2008: 78-79)

11 Uso el término 'esencialismo' en el sentido de Wittgenstein, como el intento de definir o poner límites al significado. 
paso de una sociedad pre-hegemónica a una hegemónica- como resultado de un evento al modo de Heidegger, o bien como producto de las prácticas discursivas, al modo pragmático. La primera opción pondría a Laclau en la situación de intentar pensar la política como un ámbito cercado por condiciones trascendentales, como lo sugiere Butler. La segunda, en una posición en la que las prácticas discursivas han producido una transformación que se traduce en que las propias prácticas queden cercadas, en la época moderna, por una semiología del discurso que ya no pueden trascender. En este caso, como dice Marx a propósito de los economistas clásicos: "ha habido historia, pero ya no la hay" (Marx 1975: 99).

\section{Lo social como prácticas discursivas}

Según vimos, para Laclau no hay prácticas no discursivas y aunque no lo aclara del todo, eso significa que los elementos o momentos, los significantes flotantes o vacíos cobran existencia como enunciados. Dice, junto a Mouffe: "El tipo de coherencia que atribuimos a una formación discursiva es cercano -con las diferencias que especificaremos luego- al que caracteriza al concepto de 'formación discursiva ' elaborado por Foucault: la regularidad en la dispersión." (Laclau y Mouffe 1987: 119) El único punto en el que difieren de Foucault, como lo anuncian posteriormente a la cita precedente, es que éste último reconoce la existencia de prácticas no discursivas. (Laclau y Mouffe 1987: 121) Ahora bien, en Arqueología del saber sostiene Foucault: "Lo que se ha descrito como formación discursiva son en un sentido estricto grupos de enunciados" (Foucault 2002: 194-195). ${ }^{12}$

Si no hay prácticas no discursivas y las formaciones discursivas consisten en juegos de lenguaje, esto es, en reglas y acciones entretejidas, eso no implica que lo discursivo agote las prácticas, y cabe interpretar la salvedad de Foucault en ese sentido. Una de las contribuciones de Heidegger al pensamiento contemporáneo, compartida por Wittgenstein, Searle y otros filósofos es que el lenguaje supone un background de saberes no explícitos, prácticos, no teóricos, a partir del cual las prácticas discursivas pueden llevarse a cabo.13 Dice Searle. "Piensen, por ejemplo, en la ocurrencia del verbo «cortar» en sentencias como 'Sally cortó el pastel' o 'Bill cortó el césped' o 'El sastre cortó la tela'; o piénsese en el verbo 'crecer' en sentencias como 'La economía americana está creciendo', o ‘Mi hijo está creciendo', o ‘El césped está creciendo'. En una expresión literal normal de cada una de estas sentencias, cada verbo tiene un significado constante. Pero en cada caso el mismo

\footnotetext{
${ }^{12}$ Según la Real Academia de la lengua 'discurso' es una "serie de las palabras y frases empleadas para manifestar lo que se piensa o siente." Y 'enunciado' una "secuencia finita de palabras delimitada por pausas muy marcadas, que puede estar constituida por una o varias oraciones."

13 El apartado 33 de Ser y tiempo lleva por título "El enunciado en cuanto modo derivado de la interpretación."
} 
verbo determinará distintas condiciones de verdad (o, más en general, de satisfacción), pues lo que cuenta como cortar o crecer variará de un contexto a otro" (Searle 1997: 142). Agrega Searle que no hay nada en el significado literal de las oraciones que nos diga cómo interpretarlas y que entendemos el verbo en cada caso de un modo diferente porque la interpretación depende de las capacidades de trasfondo, de una apertura de mundo diría Heidegger. La tesis es que no es el contenido semántico sino el conocimiento de cómo funciona el mundo, no incluidas en el significado literal de los enunciados el que permite que se dé una interpretación lingüística, y ese conocimiento no es discursivo ni consiste en enunciados; es un conocimiento tácito, si se le pidiera a alguien que lo explicitara no sería capaz de hacerlo. ${ }^{14}$

Tal vez pensando en este problema es que, en escritos posteriores, Lacau sostiene que el mundo está constituido por prácticas sedimentadas. Dice: "El modo en que estoy presentando el argumento es que vivimos en un mundo de prácticas sedimentadas. El momento de reactivación consiste no en un momento de fundamento original, como en Husserl, sino en una decisión contingente original a través de la cual lo social es instituido. Este momento de institución de lo social a través de decisiones contingentes es lo que denomino 'lo político'." Laclau no elabora mayormente el punto, pero parece difícil sostener que las prácticas sedimentadas sean discursivas, de hecho, el concepto, como el mismo lo recuerda en el mismo texto, alude a "prácticas que se convierten en repeticiones y olvidan el momento de su institución original" (Worsham \& Olson 1999: 18)15; más bien las prácticas sedimentadas apuntan a un concepto de background afín al de Heidegger, Wittgenstein y Searle. Pero, más allá de eso, el énfasis de Laclau está puesto en el momento instituyente (el discurso) consistente en una decisión contingente que constituye un momento de 'reactivación' de lo social. Eso permite explicar en parte la ausencia de lo "instituido" y de la historia en sus análisis de lo político.

\section{Lo político como articulación de elementos o fragmentos}

Como vimos, el punto de partida de Laclau es una totalidad social orgánica perdida que da lugar a la siguiente alternativa: “o bien esa organización es contingente y, por tanto, externa a los fragmentos, o bien, tanto los fragmentos como la organización son considerados como momentos necesarios de una totalidad que los trasciende. Es claro que sólo la primera forma de 'organización' puede ser considerada articulación; la segunda es, en el estricto sentido del término, una mediación"

\footnotetext{
14 Kuhn, al igual que Heidegger, duda de llamarlo 'conocimiento' debido a que "No tenemos acceso directo a lo que es aquello que sabemos, no tenemos reglas de generalización con que expresar este conocimiento" (Kuhn 1980: 299).

$15 \mathrm{El}$ énfasis es agregado.
} 
(Laclau y Mouffe 1987: 106).

Articulación-externa-contingente-entre-fragmentos versus mediación-interna-necesaria-deuna-totalidad, es la disyuntiva que nos presenta Laclau. Dicha visión ve en las cosmovisiones religioso-metafísicas del mundo el sentido que sostenía a las comunidades tradicionales, y en la pérdida de su vigencia el origen de la fragmentación propia de la modernidad. No es necesario, sin embargo, aceptar los "cuernos del dilema" que nos plantea Laclau; la totalidad hegeliana no es la única alternativa a la fragmentación. Como veíamos antes, la tradición fenomenológica, en sus distintas versiones, sostiene el concepto de "mundo", un tipo de totalidad contingente, no conceptual, que en sus versiones más sofisticadas reivindica la agencia de las prácticas. Lefort, en la estela de Merleau-Ponty, ha defendido la condición simbólica de lo social, entendiendo por tal las formas que adquieren las relaciones sociales en distintos momentos históricos. Para Lefort el carácter simbólico de lo social supone un conjunto de principios generadores de las relaciones que los hombres mantienen entre sí y con el mundo, conjunto al que denomina forma de sociedad, esto es, una estructura legítima de poder y un conjunto de normas implícitas que establecen qué es justo o injusto, bueno o malo, deseable e indeseable, noble y vil (Lefort 1986: 9).

Charles Taylor, a su vez, ha sostenido con gran consistencia la idea que la Edad Moderna supone un trasfondo de orden moral que ha estructurado un imaginario social, implicando no la disolución sino un nuevo tipo de comunidad. En los cuatro últimos siglos dicho imaginario ha crecido en extensión y en intensidad: un orden de beneficios mutuos entre individuos que asegura la libertad sobre la base de derechos para todos, y si bien qué significa igualdad está sujeta a variación, supone el rechazo a todo orden jerárquico; se centra en las necesidades de la vida ordinaria, y no ya en la búsqueda de la virtud ni en el privilegio de la figura del héroe o el santo (Taylor 2006). Taylor se aleja de una interpretación de la modernidad como "sustracción", de acuerdo a la cual de la caída de las visiones religioso-metafísicas del mundo restarían individuos sin un mundo común, y los valores estarían alojados en la subjetividad. Para una visión como la de Taylor es imposible prescindir de los marcos referenciales de los valores, del horizonte dentro del cual las cosas cobran significado para los hombres.

No obstante sus planteamientos sobre la fragmentación moderna, Laclau alude al "imaginario social" de la modernidad. Lo expresa del siguiente modo: "El momento clave en los comienzos de la revolución democrática puede ubicarse en la Revolución Francesa, ya que, como lo ha señalado François Furet, fue al nivel del imaginario social que surgió entonces algo verdaderamente nuevo con 
la afirmación del poder absoluto del pueblo. Es allí donde, según él, se sitúa la verdadera discontinuidad: en el establecimiento de una nueva legitimidad, en la invención de la cultura democrática." (Laclau y Mouffe 1987: 173-174) De acuerdo al pasaje anterior la "fragmentación" moderna correspondería a una cultura, esto es, a un sentido compartido respecto al origen y legitimidad del poder, y esto implica no la fragmentación sino una totalidad en la que la "articulación" no puede ser "externa" a los elementos articulados, sino parte de dicha cultura.

\section{La relación particular-universal como contaminación}

El concepto que utiliza Laclau para definir la relación entre universalidad y particularidad es “contaminación”. Este término quiere indicar que no hay universalidad en sentido propio, solamente una universalidad consistente en una cadena de equivalencias en torno a una particularidad que toma el lugar de la universalidad representando al resto de las particularidades, manteniendo su condición particular. La relación universalidad-particularidad es estratégica en el pensamiento de Laclau, puesto que de allí deriva la condición no suprimible del antagonismo, al tiempo que hace explícito el significado que para él tiene este término. "Si lo concreto siempre contamina lo abstracto ¿no ocurre entonces que un particular que se afirma como universal, lejos de ser un caso especial limitado al Terror jacobino, pasa a ser un rasgo de toda vida social, de modo tal que el antagonismo, tal como hemos mantenido siempre, es un rasgo inerradicable de lo social?" (Laclau 2011:197).

Ahora bien, la relación universalidad-particularidad es de representación: "Pero, en tanto la universalidad de la comunidad sólo es alcanzable a través de la mediación de una particularidad, la relación de representación deviene constitutiva" (Laclau 2011: 64). El propio Laclau ha deconstruido, en otro contexto, lo que llama "la lógica de la representación". Dice: "si lo representado necesita la relación de representación, es porque su identidad es incompleta y debe ser suplementada por el representante. Esto significa que el papel del representante no puede ser neutral, y él contribuirá en algo a la identidad de aquellos que representa. Luego, la relación de representación será, por razones lógicas esenciales constitutivamente impura; el movimiento de lo representado a lo representante tendrá que ser necesariamente suplementado por un movimiento en la dirección opuesta" (Laclau 1996a: 51).

Lo representado tiene una identidad incompleta cuya carencia deber ser completada por un suplemento no neutral. ¿Qué puede significar esto, sino que la contribución del representante a la identidad del representado supone, al menos, la no exterioridad entre ambos? Traducido al caso: entre la universalidad (representado) y su suplemento, la particularidad (representante), tiene que haber 
algún tipo de afinidad. Sin embargo, como vimos, Laclau sostiene que la relación entre particular y universal es de "contaminación"; lo particular contamina a lo universal, y ahí radica el corazón de la hegemonía. Demás está decir que la contaminación es una relación invasiva en todas sus acepciones: alterar, contagiar, pervertir, profanar.

Respecto al movimiento en la dirección opuesta dice Laclau: 1) "cuanto más extensa sea la cadena de equivalencias que un sector particular viene a representar y cuando más se transformen sus objetivos en un nombre para la emancipación global, tanto más vagos serán los vínculos entre ese nombre y su significado original específico y más se aproximará al estatus de un significante vacío; 2) como, no obstante, esta total coincidencia de lo universal con lo particular es en última instancia imposible-dada la inadecuación constitutiva de los medios de representación-, siempre quedará un residuo de particularidad" (Laclau 2011: 63-64). 16

Claramente hay una disonancia entre la no neutralidad del representante en el primer texto con la inadecuación constitutiva de los medios de representación del segundo. Que hay aquí un problema no suficientemente aclarado por Laclau lo indica, a mi modo de ver, el siguiente texto, en el que se sugiere un enfoque totalmente distinto: "Ya está operando una dimensión de universalidad en los discursos que organizan las demandas particulares y las políticas orientadas a la resolución de temáticas particulares, pero es una universalidad implícita y no desarrollada, incapaz de proponerse como un conjunto de símbolos que pueda agitar la imaginación de vastos sectores de la población. La tarea por delante es expandir esas semillas de universalidad...” (Laclau 2011: 305).

Este texto es, contrariamente a numerosas declaraciones en las que Laclau toma distancia de Hegel, cabalmente hegeliano: la universalidad está en la particularidad, pero "en sí”, no "para sí”, lo que implica totalidad y mediación, no fragmentación ni articulación. Y lo menos que se puede decir es que colisiona frontalmente con la noción de "contaminación" para caracterizar la relación universal-particular; lo particular, implícitamente universal, no "se afirma" como universal, no toma su lugar, sino que se desarrolla como tal, llega a ser lo que implícitamente es, lo cual quiere decir que no es el caso que "la separación entre lo universal y lo particular es infranqueable" (Laclau 1996: 53); más aún, cabría sostener que no caben aquí relaciones de "representación" entre particular y universal. En esta línea, podemos pensar que el imaginario social igualitario moderno al que se refería Laclau en el texto antes citado constituye aquel universal "implícito" en los particulares.

16 El énfasis es agregado. 


\section{La decisión como liderazgo y fuerza}

Otro concepto que Laclau moviliza para afirmar el carácter antagónico-hegemónico de la política es la decisión. El término indecibilidad alude a una decisión que no puede ser resuelta a través de un algoritmo. Toda estructura está abierta a la contingencia y a la dislocación y eso implica que hay una pluralidad de posibilidades y una posibilidad real que depende de una decisión. Esa decisión es libre en el sentido de que no depende de ninguna determinación estructural, el momento de la decisión es un fiat y el sujeto es la distancia entre la indecibilidad de la estructura y la decisión. "Pero esa decisión puede solamente ser hegemónica, esto es, que está a) autofundada; b) es excluyente, en cuanto implica la represión de decisiones alternativas; y c) está internamente escindida porque es al mismo tiempo esta decisión, pero también una decisión” (Laclau 1996a: 62). Siguiendo a Kierkegaard y a Derrida, Laclau llega a decir que "el momento de la decisión es el momento de la locura" (Laclau 1996a: 55).

La dicotomía es, pues, razón algorítmica, esto es, auto-fundada versus decisión auto-fundada; se ha desplazado un absoluto por otro. ¿No estamos nuevamente en el terreno del sujeto cartesiano? La 'distancia' entre la estructura y la decisión ¿no es equivalente a la distancia en relación al mundo del sujeto cartesiano? ¿No estamos de lleno en la metafísica de la presencia? Igualmente, tanto en la razón algorítmica como en la decisión está supuesto un sujeto monológico: en el primer caso, es la determinación del caso de acuerdo al algoritmo (el método); en el segundo, por un hágase (fiat), y en ninguno de los dos está exigida la presencia de otros. En efecto ¿es posible pensar como locura una decisión colectiva? Una decisión colectiva, un sujeto colectivo, supone algún tipo de acuerdo entre los concernidos antes del 'corte', producto de la deliberación, el que constituye un límite a la libertad, una libertad situada, y no un momento de locura, esto es, absolutamente libre, como lo sostienen Derrida-Laclau. De modo que la decisión como locura es subjetiva-individual y ciertamente puede ser impuesta a un colectivo, pero no decidida por éste.

Laclau deriva del carácter algorítmico de la razón no solamente el momento de decisión autofundado sino su carácter de fuerza: "Pienso que he mostrado en ese trabajo que la persuasión, precisamente porque nunca está presente un argumento que tendría que ser aceptado algorítmicamente, implica, si se quiere, un elemento de fuerza." (...) "Ud. persuade por algo menos que un tipo de demostración racional. ¿Qué es este algo menos? Aquí puede haber muchas respuestas posibles y todas ellas tendrían que ser evaluadas dependiendo de la situación. Por ejemplo, Ud. puede provocar la simpatía del oyente. Ud. puede, por otro lado, presentar el argumento tan fuertemente que 
puede intimidar al oyente, y Ud. conoce todo el rango de esas posibilidades" (Worsham \& Olson1999: $5)$.

Es de notar que los ejemplos aducidos por Laclau suponen una comunicación oral, directa, entre hablantes y oyentes, la que ciertamente puede generar simpatía e intimidación, pero que pierden casi toda su 'fuerza' en espacios públicos formales, institucionalizados, los que no excluyen, por cierto, la retórica y la persuasión, pero bajo formas que hacen implausible asociar persuasión y fuerza, como es el caso de la ciencia, por ejemplo. Kuhn, entre otros, ha argumentado que, aunque la lógica ni la observación no sean compulsivas, eso no implica que la elección de teorías no sea argumentada de acuerdo a razones. Dice: "Decir que, en materia de elección de teorías, la fuerza de la lógica y la observación no pueden en principio ser compulsivas ni es descartar la lógica ni la observación ni insinuar que no haya buenas razones para defender una teoría más que otra" (Lakatos y Musgrave 1995: 395). Y también: "Referirse a la persuasión como algo a lo que recurren los científicos no es insinuar que no hay buenas razones para elegir una teoría con preferencia a otra" (Ibíd.: 429). Rorty, por otra parte, distingue las conversaciones, epistemológicas de las hermenéuticas. Las primeras se distinguen por tener un acuerdo previo acerca de cómo dirimir las diferencias; en la segunda falta ese acuerdo previo y la conversación misma va salvando las diferencias, pero en ninguno de los dos casos está excluida la argumentación (Rorty 1983).

Laclau asume, por el contrario, una concepción de la razón como algoritmo y dado que los argumentos no pueden ser compulsivos, opta por la compulsión de la decisión subjetiva que, entiende, está acompañada de la retórica como fuerza. La consecuencia de lo anterior parece inevitable: la hegemonía la ejerce un líder carismático no solamente sobre "ellos" sino también sobre "nosotros". ${ }^{7}$

\section{Esencialismo y filosofía oracular}

Laclau insiste una y otra vez en poner su proyecto orientado a conceptualizar lo político como antiesencialista, haciendo referencia con frecuencia a la obra del segundo Wittgenstein. Pero, como hemos visto, termina por delimitar el concepto de lo político como antagonismo y hegemonía. Ese intento se aleja de Wittgenstein en varios aspectos: en primer lugar, para éste el significado lingüístico se genera en el uso de las expresiones en distintos juegos de lenguaje, inseparables de formas de vida; en segundo lugar, es un intento vano tratar de fijar dicho significado al margen de esas formas de

17 No deja de ser sintomático que Laclau sostenga que "El propio Perón (....) estaba en las condiciones ideales para pasar a ser un 'significante vacío' que encarnara el momento de universalidad en la cadena de equivalencias que unificaba al campo popular” (Laclau 1996: 101). 
vida; eso implica, en tercer lugar, que las prácticas mismas van delimitando sus límites y son, en ese sentido, auto-referentes. Si eso es así, querría decir que, según la orientación pragmática de Wittgenstein, son las prácticas las que definen el significado de lo político, y de ese modo "extendemos nuestro concepto [...... como cuando al hilar trenzamos una madeja hilo a hilo" (Wittgenstein 1988: 89). ${ }^{18}$

Merleau-Ponty asume una orientación pragmática que nos interesa especialmente, dado que, como veremos, tiene una interpretación de la obra de Saussure diferente a la de Laclau. Un tema relevante en la obra de este filósofo es lo que él llama "la unidad de la historia y la filosofía", la cual quiere evitar la alternancia de la filosofía como simple lectura de una historia ya hecha y como sujeto único de la misma. Merleau-Ponty ve dicha unidad en el concepto de praxis en la obra de Marx. Para éste "el sentido histórico es inmanente al acontecimiento interhumano y frágil como él" (MerleauPonty 2006: 34). Lo que Marx llama praxis es ese sentido que se esboza espontáneamente en el entrecruzamiento de las interacciones con los otros y con la naturaleza. Marleau-Ponty ve el renacimiento contemporáneo de una concepción similar, ajena totalmente al pensamiento de Marx, en la lingüística de Saussure. La teoría del signo, tal como la elabora la lingüística implica una teoría del sentido histórico que va más allá de la alternativa entre las cosas y las conciencias. En el acto de hablar el sujeto atestigua su autonomía y, al mismo tiempo y sin contradicción es tributario de la comunidad lingüística. Hay allí una auto-constitución que permite comprender en la historia la unión de la contingencia y el sentido. En cada institución, al igual que en la lengua, los individuos se incorporan en un sistema simbólico, sin que tengan necesidad de concebirlo.

Cada acto de expresión no se limita a gastar una capacidad expresiva acumulada en la lengua, sino que recrea una y otra, manifestando el poder que tienen los sujetos hablantes de sobrepasar los signos hacia el sentido. "Los signos no solamente evocan para nosotros otros signos y así sucesivamente, el lenguaje no es una especie de prisión en la que estemos encerrados, o una especie de guía que habría que seguir ciegamente, puesto que, en la intersección de todos esos gestos lingüísticos, aparece por fin lo que quieren decir y a qué nos dispone un acceso tan completo que nos parece no tener ya necesidad de ellos para referirnos a él" (Merleau-Ponty 1964: 95). El lenguaje, al igual que el cuerpo, no está al servicio del sentido, pero tampoco gobierna al sentido. "La significación -dice Merleau-Ponty- devora los signos” (Merleau-Pony 2002: 214). Al igual que en

18 Más adelante agrega: “¿Pues de qué modo está cerrado el concepto de juego? ¿Qué es aún un juego y qué no lo es ya? ¿Puedes indicar el límite? No. Puedes trazar uno: pues no hay aún ninguno trazado. (Pero eso nunca te ha incomodado cuando has aplicado la palabra 'juego')". 
la expresión estética, los actos de habla erradican los signos de su existencia empírica y los trasportan a otro mundo; el sentido está preso en la palabra y ésta es la existencia exterior del sentido.

Para Gadamer hay en el lenguaje una tensión inerradicable entre la tendencia a la generalidad conceptual y el significado pragmático, y lo que allí se expresa es la particularidad de una experiencia. Con la disolución nominalista de la lógica clásica de la esencia la concepción del lenguaje entró en un estadio nuevo. Adquirió un valor positivo la posibilidad de articular las cosas de forma distinta, según sus coincidencias y diferencias. Si la relación de género y especie no se puede legitimar desde la naturaleza de las cosas sino en relación con el hombre, los distintos lenguajes pueden hacerse valer como formas variantes de la experiencia histórica, guiándose según intereses y necesidades (Gadamer 1977). De allí que para Gadamer no haya un lenguaje de la metafísica, lo que hay es nuestro lenguaje que sin duda está formado dentro de las tradiciones, pero vive en una variedad de transformaciones y en múltiples niveles. "La lengua — dice Gadamer - se crea en cada conversación de nuevo" (Gadamer 2001: 206). ${ }^{19}$ También: "El lenguaje no es una convencionalidad reelaborada ni el lastre de los esquemas previos que nos aplastan, sino la fuerza generativa y creadora capaz de fluidificar una y otra vez ese material” (Gadamer 1992: 201). ¿Dónde está localizada la multiplicidad del significado? se pregunta Gadamer. “¿No tiene que ser encontrado en la constitución del sentido que toma lugar en tomar y dar del lenguaje, y no en la factualidad de los signos mismos? (Gadamer 1989: $115) .^{20}$

Merleau-Ponty, como Wittgenstein y Gadamer, cada quién a su modo, asumen una posición pragmática frente al lenguaje, según la cual el significado se origina en juegos de lenguaje, actos de expresión, conversaciones, como quiera que se los llame, en interacciones que lo "extienden"

\footnotetext{
19 "En el hablar queda siempre la posibilidad de superar la propia tendencia objetivadora, como Hegel supero la lógica del entendimiento, Heidegger el lenguaje de la metafísica, los orientales superan la diferencia de los ámbitos del ser y los poetas todo lo dado en general. Más, superar significa: poner en uso" (Gadamer 2002: 82).

${ }^{20}$ Consideraciones por el estilo no son exclusivas de filósofos. A más del ya aludido Barthes, se puede citar a Benveniste:"È. B. Planteo, de hecho, que hay dos dominios o dos modalidades de sentido, que distingo respectivamente como semiótica y semántica. El signo saussuriano es en realidad la unidad semiótica, o sea la unidad dotada de sentido. Se reconoce lo que tiene un sentido; todas las palabras que hay en un texto francés tienen, para quien posee esta lengua, un sentido. Pero importa poco que se sepa cuál es dicho sentido y no hay que cuidarse de ello. Tal es el nivel semiótico: ser reconocido como poseedor o despojado de sentido. Esto se define diciendo que sí o que no.”

P. D. En tanto que la semántica...

È. B. La semántica es el "sentido" resultante del encadenamiento, de la adecuación a la circunstancia y del ajuste de los diferentes signos entre ellos. Es absolutamente imprevisible. Es un abrirse al mundo. En tanto que la semiótica es el sentido cerrado sobre sí mismo y contenido, en cierto modo, en sí mismo.

P. D. Es decir que, en suma, el sentido semiótico es un sentido inmediato. En cierta manera sin historia ni ambiente.

È. B. Sí, así es. Se determina por unidad aislada: se trata de averiguar, por ejemplo, si la palabra role es aceptada como significativa. Sí, role sí; ril no" (Benveniste 1977: 23-24).
} 
(Wittgenstein 1988: 89), "fluidifican” (Gadamer 1992: 201) o "recrean” (Merleau-Ponty 1964: 95), sin quedar atados a formas trascendentales que le pongan límites.

Como hemos visto, para Laclau las prácticas discursivas consisten en un conjunto de reglas anónimas inmanentes a las mismas. El modelo semiológico implica que los agentes no tengan un conocimiento teórico de las reglas de dichas prácticas. Según lo recuerdan Hubert Dreyfus y Paul Rabinow en su libro sobre Foucault, se han propuesto dos modelos alternativos para explicar cómo las reglas gobiernan las formaciones lingüísticas. Por una parte, Chomsky y Levi-Strauss sostienen que las reglas son innatas y son instadas en el cerebro. Por otra, Heidegger y Wittgenstein piensan que las prácticas lingüísticas mismas tienen el poder de sostenerse y perpetuarse y que las reglas son aproximaciones descriptivas efectuadas por profesores de escuela y lingüistas. Pero: "En ningún caso se puede decir que en realidad las reglas mismas 'gobiernan' 'operan' 'determinan' o 'limitan' la conducta. Son o las neuronas o las prácticas sociales las que tienen el poder causal" (Dreyfus y Rabinow 1982: 82).

Laclau delimita o define lo político como antagonismo y hegemonía, y pese a sus pretensiones, asume una posición esencialista, por cierto, no desde un punto de vista metafísico. Pero como lo puso de manifiesto Cassirer en su momento, el esencialismo, originado en la metafísica antigua, sobrevive a ésta en la pretensión de delimitar los conceptos de acuerdo a lo común de una diversidad, la que no puede evitar que la selección de lo que es común sea pensada, al mismo tiempo, como la forma que garantiza la conexión causal y teleológica de las cosas particulares (Cassirer 1953). Los argumentos de Wittgenstein se orientan, a su vez, a mostrar la imposibilidad de encontrar algo común en la gran diversidad de significados que adquieren los términos, de acuerdo a los distintos juegos de lenguaje (Wittgenstein 1988: 85 y ss.).

¿Puede el filósofo establecer el significado de las prácticas? ¿Puede corregirlas? En verdad el filósofo esencialista se enfrenta no solamente al sentido implícito en las prácticas sino también a otros filósofos esencialistas, cada cual con sus propias propuestas teóricas. En el terreno de la filosofía política, y limitándonos al pensamiento contemporáneo, se encuentra una variedad de posiciones acerca de qué es la política: Schmitt, Arendt, Habermas, Rancière, Badiou, para nombrar solamente a algunos. $^{21}$

\footnotetext{
${ }^{21}$ Cabe sostener que los proyectos de Laclau y Habermas, respectivamente, constituyen concepciones que neutralizan la
} 
¿Quién decide, pues, qué es la política? La respuesta a esto es que se aplica a la política lo mismo que a la oración, de acuerdo al análisis de Peter Winch. ¿El humilde publicano hace lo mismo que el soberbio fariseo? ¿Ambos están orando o uno ora y otro blasfema? Dar respuesta a esa pregunta no es un derecho que el científico social ni el filósofo puedan arrogarse. Solamente la práctica de la oración en el contexto histórico pertinente puede hacerlo y el científico social y el filósofo tienen que acoger esa respuesta (Winch 1972: 82 y ss.). De otro modo se ponen en la posición de teóricos oraculares, mediadores de un conocimiento que les ha sido concedido en exclusividad.

¿La filosofía es, entonces, tributaria de la historia? La filosofía ¿“deja todo como está”? (Wittgenstein 1988: 129). No es necesario seguir en esto a Wittgenstein, más bien a filósofos como Merleau-Ponty y Lefort en su concepción de la "unión de la historia y la filosofía." Lefort expresa dicha unión del siguiente modo: "elevar a la reflexión una práctica que ciertamente no es muda pero que, por necesariamente difusa, ignora su alcance en la generalidad de lo social y de la que por naturaleza no pueden extraer su verdad aquellas formaciones políticas que sólo se dedican a usarla y, en parte, y no sin éxito, a desarmar" (Lefort 2004: 207).

\section{Referencias bibliográficas}

Benveniste E (1999), Problemas de lingüistica general II, México, Siglo XXI Editores.

Boucher G. (2008), The Charmed Circle of Ideology. A Critique of Laclau and Mouffe, Butler and Żižek, Melbourne, Re.press.

Butler J. (2011), "Replantear lo universal", en Contingencia, hegemonía, universalidad, Buenos Aires, Fondo de Cultura Económica.

Cassirer E. (1953), Substance and Function and Einstein's Theory of Relativity, Dover Publications, Inc., Chicago.

Derrida J. (1972), Positions, Paris, Minuit.

apertura de mundo de las prácticas: el primero a través de una semiología del discurso y el segundo a través de una pragmática universal, ambas formales. En Habermas, el consenso está inscrito en las condiciones de posibilidad del entendimiento; en Laclau el antagonismo en una lógica de cuño semiológico. Es cierto que Habermas asume una perspectiva pragmática; sin embargo, la hermenéutica queda neutralizada por el carácter formal de la misma. Laclau, como hemos visto, toma acríticamente la diferencia ontológica de Heidegger: lo óntico es cubierto por lo ontológico sin poder trascenderlo. Reconocido o no, hay en ambos una pretensión de haber finalmente develado el modo cómo se constituye el orden político-social. Tanto la pragmática universal como la lógica hegemónica son condiciones trascendentales no rebasables por las prácticas, por tanto, ahistóricas. Ambos usan el término "cuasi-trascendental", pero en sentidos distintos: en Habermas indica que lo trascendental es producto de una ciencia reconstructiva falible de las condiciones del entendimiento, en Laclau que las condiciones de posibilidad son también condiciones de imposibilidad. 
Dreyfus H. L. y Rabinow P. (1982), Michel Foucault. Beyond Structuralism and Hermeneutics, Chicago, The University of Chicago Press.

Foucault M. (2002), Arqueología del saber, Buenos Aires, Siglo XXI Editores.

Gadamer H. G. (1977), Verdad y método, Salamanca, Sígueme.

(1989), "Hermeneutics and Logocentrism", en Dialogue \& Deconstruction. The Gadamer-Derrida Encounter, edited by Diane P. Michelfelder \& Richard E. Palmer, New York, State University of New York Press, Albany.

(2001), El giro hermenéutico, Madrid, Cátedra.

método II, Salamanca, Sígueme.

(1992), “Hasta qué punto el lenguaje preforma el pensamiento?”, en Verdad y

García J. F. (2016), "Las prácticas como apertura de mundo: semántica, pragmática y diferencia política”, Revista de Filosofía, Volumen LXXII, Santiago, Universidad de Chile.

Habermas J (2005), Facticidad y validez, Madrid, Editorial Trotta.

Heidegger M (1997), Ser y tiempo, Santiago, Editorial Universitaria.

(1992), ¿Qué es metafisica? y otros ensayos, Buenos Aires, Ediciones Fausto.

(2016), La proveniencia del arte y la determinación del pensar" Conferencia dada el 4 de abril de 1967 en la Academia de las ciencia y de las artes de Atenas. Traducción de Breno Onetto (https://www.academia.edu/6719584/ visitada el 22/01/2016).

Kant I (2006), Crítica de la razón pura, México, Taurus.

Kuhn Th (1995), "Consideración en torno a mis críticos", en Imre Lakatos y Alan Musgrave La crítica y el desarrollo del conocimiento, Barcelona, Grijalbo.

Económica.

(1980), La estructura de las revoluciones cientificas, México, Fondo de Cultura

Laclau E., Mouffe Ch. (1987), Hegemonía y estrategia socialista. Hacia una radicalización de la democracia, Madrid, Siglo XXI Editores.

Laclau E. (1993), Nuevas reflexiones sobre la revolución en nuestro tiempo, Buenos Aires, Nueva Visión.

Aires, Ariel.

(1996), El sujeto de la política, política del sujeto”, en Emancipación y diferencia, Buenos

(1996a), "Deconstruction, Pragmatism, Hegemony" en Deconstruction and Pragmatism,

edited by Mouffe Ch, New York, Routledge.

(2011), "Estructura, historicidad y lo político", en Contingencia, hegemonía, 
universalidad, Buenos Aires, Fondo de Cultura Económica.

Lefort Claude (2004), La incertidumbre democrática, Barcelona, Antropos.

(1986), Essais sur le politique. XIX-XX siécles, Paris Collection Esprit.

Marx K (1975), El Capital, Tomo I/Vol. 1, Buenos Aires, Siglo XXI Argentina Editores.

Merleau-Ponty M (2002), Fenomenología de la percepción, Madrid, Editorial Nacional.

(1964), Signos, Barcelona, Seix Barral.

(2006), Elogio de la Filosofía seguido del Lenguaje Indirecto y Las Voces del

Silencio, Buenos Aires, Nueva Visión.

Rorty R (1983), La filosofía y el espejo de la naturaleza, Madrid, Ediciones Cátedra.

Searle J. (1997), La construcción social de la realidad, Buenos Aires, Paidós

Taylor Ch. (2006), Imaginarios sociales modernos, Barcelona, Paidós.

Trifonas P. P. (2001), Barthes and The Empire of Signs, Ikon Books UK, Cambridge, Totem Books USA.

Winch P. (1972), Ciencia social y filosofía, Buenos Aires, Amorrortu.

Wittgenstein L. (1988), Investigaciones filosóficas, Barcelona, Editorial Crítica.

Worsham, L., \& Olson, G. (1999), "Hegemony and the Future of Democracy: Ernesto Laclau's Political Philosophy", JAC: A Journal of Rhetoric, Writing, Culture and Politics, 19, 1-34. 